\title{
Redes sociais digitais como ferramenta no processo de ensino-aprendizagem
} interdisciplinar: usando o Facebook no ensino técnico integrado ao médio

\author{
Digital social networks as a tool in the interdisciplinary teaching-learning \\ process: using Facebook in technical education integrated to high school
}

\section{Las redes sociales digitales como herramienta en el proceso interdisciplinario de enseñanza-aprendizaje: el uso de Facebook en la educación técnica integrada a la escuela secundaria}

Dockhorn, Danila Cristiane Marques Sanches ${ }^{1}$ (Goioerê, PR, Brasil) ORCID ID: https://orcid.org/0000-0002-0771-2671

Silva, Júlio César da² (Mafra, SC, Brasil) ORCID ID: https://orcid.org/0000-0002-6655-284X

Domingues, Maria José Carvalho de Souza ${ }^{3}$ (Blumenau, SC, Brasil) ORCID ID: https://orcid.org/0000-0001-7771-144X

\section{Resumo}

As redes sociais têm ocupado um espaço cada vez maior nas atividades dos jovens. $O$ sucesso do Facebook é, em grande parte, pela possibilidade de aproximação entre as pessoas e a facilidade de acesso. A utilização das redes sociais, especialmente o Facebook, é um tema pertinente à escola, tendo em vista que serve para auxiliar no processo de ensino-aprendizagem. Portanto, este trabalho tem por objetivo analisar o uso de um grupo no Facebook para apoiar o processo de ensinoaprendizagem em uma escola de ensino médio integrado ao técnico profissional. A pesquisa foi realizada com 24 estudantes e um professor da matéria Projeto Integrador I na classe do $1^{\circ}$ ano do Curso Técnico em Vestuário. Caracteriza-se como um estudo de caso. A base do trabalho é o uso de depoimentos e análises de posts na página do grupo na rede social. Realizou-se a análise qualitativa, empregando o uso de técnicas de análise de conteúdo e a utilização de nuvem de tags com o auxílio do aplicativo Wordle para análise de dados. Como resultados destacam-se: o uso do Facebook é avaliado como uma importante ferramenta de colaboração entre alunos e professores. A autoria dos alunos também é destaque, assim como o dinamismo na interação entre os alunos. Bem como uma ferramenta para melhorar a relação da classe, para permitir a construção de um ambiente colaborativo e ao mesmo tempo crítico.

Palavras-chave: Ensino por multimeios. Atividades de ensino-aprendizagem. Educação Profissional Integrada.

\begin{abstract}
The social networks have occupied growing space in youth activities. The success of Facebook is targeted largely by the possibility of rapprochement between people and ease of use. To know how social networks, especially Facebook, can help in the teaching-learning process is still new in the school. Therefore, this paper aims to analyze the use of a Facebook group to support the teaching-learning process on schools in high school. The research was conducted with 24 students and a teacher of the matter Integration Project I, in the class of the 1st year of the higher secondary technical-professional education. It is characterized as a case study. The research's basis is the use of testimonials and analysis of posts on the group's page in the social network. Through qualitative analysis employed the use of techniques of content analysis and the Wordle application usage for data analysis on the network. As results stand out: the use of Facebook is valued as an important collaborative tool between students and teachers and students. The authorship of the students is also highlighted, as well as more dynamic, interaction among students. As well as a tool to improve the class relationship, to allow the construction of a collaborative environment and at the same time critical.
\end{abstract}

Keywords: Multimedia teaching. Teaching and learning activities. Higher secondary technicalprofessional education.

\footnotetext{
1 Docente no Instituto Federal do Paraná. danilasanches@gmail.com.

2 Docente e Pesquisador Programa de Programa de Mestrado Profissional em Administração (PMPA). Universidade do Contestado. profjuliosilva72@gmail.com.

3 Professora titular da Universidade Regional de Blumenau -FURB. mariadomingues@furb.br.
} 


\section{Resumen}

Las redes sociales han ocupado un espacio cada vez mayor en las actividades de los jovenes. El éxito de Facebook se debe, en gran parte, a la posibilidad de unir a las personas y la facilidad de uso. Cómo utilizar las redes sociales, especialmente Facebook, es un tema relevante para la escuela, en vista de que sirve para ayudar en el proceso de enseñanza-aprendizaje. Por lo tanto, este trabajo tiene como objetivo analizar el uso de un grupo de Facebook para apoyar el proceso de enseñanzaaprendizaje en una escuela secundaria integrada con el técnico profesional. La investigación se llevó a cabo con 24 estudiantes y un profesor de la asignatura Proyecto Integrador I en la clase de 1er año del Curso Técnico en Vestuario. Se caracteriza como un caso de estudio. La base del trabajo es el uso de testimonios y análisis de publicaciones en la página del grupo en la red social. Se realizó un análisis cualitativo, empleando el uso de técnicas de análisis de contenido y el uso de una nube de etiquetas con la ayuda de la aplicación Wordle para el análisis de datos. Los resultados se destacan: el uso de Facebook se evalúa como una importante herramienta de colaboración entre estudiantes y profesores. También se destaca la autoría de los alumnos, así como el dinamismo en la interacción entre ellos. Además de una herramienta para mejorar la relación de clase, para permitir la construcción de un entorno colaborativo y a la vez crítico.

Palavras-Clave: Enseñanza multimedia. Actividades de enseñanza-aprendizaje. Educación Profesional Integrada.

\section{Introdução}

Os movimentos impetrados pelo uso das tecnologias de informação e comunicação, principalmente das mídias sociais como o Facebook e o Twitter, têm sido utilizados como importantes ferramentas complementares no processo de ensino e aprendizagem.

$\mathrm{Na}$ concepção de Selwyn (2003), a amplitude da utilização dessas tecnologias está diretamente atrelada a maior oferta e consumo de computadores pessoais, internet e televisão digital. Neste sentido, destaca Waiselfisz (2007) que diversas pesquisas demonstram os resultados positivos da inclusão das tecnologias de informação e comunicação (TIC's) para a comunidade escolar nas estratégias de ensino e socialização.

Com a ampliação ainda maior da oferta de tecnologias e a utilização dos smartphones, amplia-se também o foco de utilização das ferramentas sociais online, as chamadas redes sociais, no ensino dentro e fora do espaço escolar. De acordo com Gabriel (2009), as mídias sociais são tecnologias e práticas que permitem compartilhar conteúdos, opiniões, insights, experiências, perspectivas e multimídias.

Segundo Lemos e Lévy (2010, p. 12) "as redes sociais online tornam-se cada vez mais táteis, no sentido de que é possível perceber continuamente o pulso de um conjunto de relações". Diante dessa perspectiva, esta pesquisa tem como objetivo analisar o uso de um grupo no Facebook como apoio no processo de ensinoaprendizagem.

O presente trabalho justifica-se por ampliar o debate de um tema em voga, 
Programa de Pós-graduação em Educação, Universidade Federal do Ceará

Fortaleza-CE-Brasil

principalmente por tratar-se de tecnologias pouco utilizadas pelos professores que,

por não serem usuários ativos, estão despreparados para receber alunos já familiarizados com a era digital. Lévy (1998) já concebia que antes de influir sobre o aluno, o uso dos computadores obriga os professores a repensar o ensino de sua disciplina e estar preparado para tal.

O trabalho está estruturado em cinco seções, iniciando com a presente introdução e, seguindo, a segunda seção com uma revisão da temática sobre as mídias sociais na educação. Na terceira seção, são apresentados os procedimentos metodológicos utilizados na realização da pesquisa. A quarta seção traz os resultados obtidos que respondem às principais indagações que motivaram o presente estudo. Ao final, na quinta e última seção, faz-se o fechamento do trabalho com as considerações finais e possibilidades para novas pesquisas, seguido das referências utilizadas na construção do artigo.

\section{Redes Sociais Digitais}

Em 1984, Willian Gibson criou o termo ciberespaço para se referir ao espaço baseado em dados. O prefixo ciber, a partir deste momento, passou a ser associado a todas as formas de interação mediadas por computadores. Com o advento da internet, houve um desenvolvimento do ciberespaço, como também a interação homem-tecnologia. A interação tornou-se intrínseca ao constructo tecnológico (VERMELHO; VELHO, 2016). Nesse contexto, as redes sociais digitais podem ser entendidas como programas de colaboração social, sendo um espaço comum de compartilhamento, de conhecimento, de interação e comunicação (PETTENATI; RANIERI, 2006; BRANDTZAEG; HEIM, 2007).

As redes sociais digitais representam o quarto marco da evolução da computação. Em um primeiro momento, estavam ligadas aos semicondutores e computadores institucionais, evoluindo no segundo momento para a posse do computador pessoal e num terceiro momento revolucionando a forma de interação social na internet. Por sua grande disseminação de informação e o compartilhamento rápido de posts de diversos assuntos, as redes sociais passaram a influenciar o comportamento dos jovens online e offline. Essa influência na vida das pessoas tem se tornado uma preocupação para governos, empresas, mercado e dentro das escolas e universidades (SANTAELLA, 2013). 
O Facebook é a rede social mais utilizada em todo o mundo, e funciona como um espaço de encontro, de partilha, de interação e de discussão das ideias e temas de interesse comum. Criado, em 4 de fevereiro de 2004, por Mark Zuckerberg e alguns colegas estudantes da Universidade de Harvard, o site foi desenvolvido para comunicação, envio de mensagens e publicação de fotografias. Atualmente, o aplicativo conecta os usuários baseado em seus interesses pessoais e/ou profissionais, localização, trabalho, ensino, entretenimento, esportes etc. Além disso, oferece uma ampla gama de ferramentas para entreter, informar e partilhar uma infinidade de conteúdos, possibilitando a interação dos usuários entre si ou através de comunidades virtuais temáticas (EDUCAUSE, 2007).

De acordo com Panteli (2009), o Facebook é uma rede social com um tipo de participação massiva, característica relacionada com o número de membros registrados. Quando esse número é muito elevado, provoca um efeito de aglomerado, formando um grupo sólido que tende a agir de uma forma homogênea e consistente.

Segundo Alon et al. (2004 apud PANTELI, 2009) e Valck et al. (2006 apud PANTELI, 2009), as pesquisas demonstram que o tempo que os usuários passam nas comunidades formadas nas redes sociais auxilia no desenvolvimento de laços emocionais, elevando ainda mais a frequência de acesso ao aplicativo.

Em números, o Facebook tem demonstrado um crescimento incomum. No ano de 2004, apresentava 1 milhão de usuários; no ano de 2006 cerca de 12 milhões de usuários; em 2011 já eram mais de 800 milhões de usuários. Segundo dados publicados pela empresa Socialbakers (2014), que controla as estatísticas geradas pela utilização das redes sociais na internet, em dezembro de 2014, o Facebook alcançava o número de 1,350 bilhão de usuários. Dados atualizados pela companhia Facebook, em abril de 2020, mostram um contínuo crescimento no uso da plataforma, que neste último relatório contava com 2,6 bilhões de usuários ativos. Números que reforçam a relevância de pesquisas na área de ensino-aprendizagem que fazem uso das redes sociais (MENLO PARK, 2020).

$\mathrm{O}$ crescimento exponencial deste tipo de app deu-se, em parte, pela popularização de dispositivos individuais, como tablets, smartphones e computadores pessoais que facilitaram a produção e o compartilhamento de conteúdo. No caso específico dos materiais de vídeo, em 2012, 49\% dos brasileiros consumidores de internet assistiam vídeos online. Já em 2018, o volume de adesão era de $71 \%$. Tal 
crescimento, pode ser explicado pelo engajamento dos brasileiros nas redes sociais digitais e a popularização do YouTube (BONA et al., 2019).

Para Martín-Moreno (2004), as redes sociais podem auxiliar na aprendizagem colaborativa, ao permitir maior participação dos indivíduos e, com isso, do próprio grupo. A possibilidade de uma maior participação individual e sua interação favorece a retenção de aprendizagem, bem como, a discussão crítica, oportunizando assim, maiores debates sobre o conteúdo, visto que a diversidade de cultura e experiência dos estudantes é compartilhada entre todos.

\section{$O$ uso de redes sociais como ferramenta de ensino-aprendizagem}

A utilização das redes sociais, em contexto educacional, é uma área de pesquisa que teve início em meados dos anos 2000, no entanto, teve seu pico de estudos entre 2008 e 2011, quando houve maior adesão dos usuários a este tipo de plataforma. As pesquisas foram realizadas e aplicadas nos mais variados níveis educacionais (VERMELHO; VELHO, 2016). Alguns resultados promissores, são apresentados nos trabalhos desenvolvidos por Dotta (2011), Minhoto e Meirinhos (2011), Raupp e Eichler (2012), Costa e Ferreira (2013) e ainda Quintanilha (2017), em sua maioria, citados neste trabalho.

A cibercultura foi assimilada pelos jovens e se transformou em um modelo de convergência de mídias (em um primeiro momento guiado pela TV, rádio, jornais e revistas e, posteriormente, pela internet), meios comunicacionais baseados nas trocas simbólicas mediadas por signos estritamente vinculados à evolução tecnológica, cuja característica principal é a interatividade (SODRÉ, 1996). Na concepção de Dotta (2011), o uso de redes sociais como ambientes virtuais de aprendizagem deve considerar os conceitos de colaboração, aprendizagem colaborativa e espaços colaborativos.

Patrício e Gonçalves (2010) desenvolveram uma pesquisa com alunos do $1^{\circ}$ ano da licenciatura em Educação Básica, na unidade curricular de Informação e Comunicação em Educação no Instituto Politécnico de Bragança, em Portugal, que explorou as aplicações e funcionalidades do Facebook, concluindo que o aplicativo pode ser utilizado como um recurso/instrumento pedagógico importante para promover uma maior participação, interação e colaboração dos alunos no processo educativo, além de impulsionar a construção partilhada, crítica e reflexiva de 
O estudo de Dotta (2011) também apresentou a rede social como um ambiente de aprendizagem colaborativa e identificou as formas de apropriação do espaço virtual pelos estudantes, inferindo que as características da interface podem ser responsáveis por estimular a colaboração.

No estudo realizado por Minhoto e Meirinhos (2011), a rede social digital foi utilizada como meio para criar um contexto propício à aprendizagem participativa, devido à facilidade da ferramenta para a partilha de conteúdo em múltiplos suportes. Os autores perceberam que a familiaridade dos alunos com as redes sociais pode facilitar a sua utilização em contextos escolares de aprendizagem, tendo em vista que não se faz necessária a ambientação do aluno com a ferramenta, pois já é familiar. Os alunos assimilaram imediatamente o processo e o sentimento de que a construção do conhecimento dependia da contribuição de todos e não somente do professor.

O estudo de Diógenes, Silva e Souza (2020) abordou o papel do tutor na educação profissional superior em modalidade a distância pela ferramenta Moodle, demostrando que o tutor necessita estar disposto a aprender com as conjunturas do processo de ensino-aprendizado, estar atento às alterações e atualizações que podem ocorrer na plataforma, vista como assustadora para alguns estudantes que se envergonham de dizer que estão com dificuldades em assimilar a modalidade de ensino a distância à sua vida, achado que corrobora com Minhoto e Meirinhos (2011) que a familiaridade do aluno com a plataforma facilita o processo de ensinoaprendizagem, eliminando barreiras à comunicação.

Raupp e Eichler (2012) trataram da potencialidade do uso de plataformas online, como: redes sociais, blogs, wikis e podcasts, e identificaram no Facebook as páginas e comunidades ativas que, de alguma forma, divulgam temas relacionados à química, ampliando e facilitando o acesso dos estudantes a este conteúdo.

Costa e Ferreira (2013) analisaram as mudanças, tanto nas formas de ensinar quanto nas formas de aprender nas redes sociais, mediante ao uso da metodologia de projetos educacionais. Os achados evidenciaram que as redes sociais, Twitter e Facebook, possibilitam diversas oportunidades para a criação de um ambiente de aprendizagem cooperativo e colaborativo. $O$ ambiente informal do Twitter e do Facebook está organizado como espaço de integração, comunicação, compartilhamento e colaboração entre professor-aluno. A tendência é de ambientes 
Programa de Pós-graduação em Educação, Universidade Federal do Ceará

Fortaleza-CE-Brasil

de aprendizagem efetivos, eficazes e envolventes por fazerem parte do cotidiano discente, podendo se tornar ferramentas pedagógicas. Conforme apresentado por Diógenes, Silva e Souza (2020), o aluno necessita mais do que sanar dúvidas e correção de atividades, precisa de apoio e condução ao caminho da leitura, da persistência, do salto sobre obstáculos do cotidiano, além da construção reflexiva e crítica, encaminhando-os para o desenvolvimento de um pensamento crítico acerca da realidade vivida.

Quintanilha (2017) desenvolveu uma pesquisa com universitários da geração Z, utilizando o Facebook e o YouTube, na qual foi verificada maior participação dos estudantes nas atividades propostas. Além disso, a percepção de que tais atividades foram eficazes para a construção do conhecimento. $O$ autor sugere que os professores busquem os meios de comunicação mais utilizados por cada grupo de estudantes e adaptem o processo de ensino-aprendizagem para que possa auxiliar no engajamento dos alunos.

Percebe-se que o Facebook ajuda a melhorar e ampliar as possibilidades de aprendizagem, também oferecendo ao educador outras maneiras de se relacionar e interagir com os discentes. Além disso, estreitam a relação professor-aluno e ampliam o espaço da sala de aula, permitindo que estes estudantes se tornem mais responsáveis por seu próprio aprendizado. Com o aumento da responsabilidade do aluno, evidencia-se sua autoria no processo de geração de conhecimento. $\mathrm{Na}$ concepção de Almeida (2014), o aluno constrói sua autonomia e torna-se autor na construção do seu conhecimento por meio das descobertas, de forma desafiadora e prazerosa.

Conforme Lima et al. (2015), as novas tecnologias, no contexto escolar, fortalecem a produção autoral e ajudam a transformar o conteúdo aprendido em algo criativo e não apenas em uma reprodução do que foi passado. $E$, nesse contexto, o aluno terá um ambiente propício para o desenvolvimento de habilidades e exposição de suas ideias de forma crítica por meio de textos, vídeos e outros tipos de recursos.

Fae e Sonza (2020) abordam as redes sociais como uma ferramenta midiática a serviço do consumismo. A partir daí, explicam que os adolescentes com seus corpos e mentes em formação são suscetíveis à persuasão da ideologização da tecnologia e ao discurso hegemônico, que é transmitido rapidamente e sem questionamento por meio de imagens postadas e compartilhadas incansavelmente. $O$ 
que reafirma a necessidade da ocupação destes espaços virtuais pela escola, com a finalidade de uma educação crítica voltada à realidade vivida pelos alunos combatendo à postura acrítica, alienada e consumista.

\title{
Método
}

A pesquisa caracteriza-se como um estudo de caso ao relatar a experiência da utilização de um recurso educacional. De acordo com Gil (2010), os estudos dessa natureza têm como objetivo aprofundar conhecimentos sobre determinado caso e verificar os fenômenos ocorridos.

Quanto à abordagem, trata-se de uma pesquisa qualitativa. Richardson (1989, p. 39) conceitua os estudos qualitativos como:

\begin{abstract}
Os estudos que empregam uma metodologia qualitativa podem descrever a complexidade de determinado problema, analisar a interação de certas variáveis, compreender e classificar processos dinâmicos vividos por grupos sociais, contribuir no processo de mudança de determinado grupo e possibilitar, em maior nível de profundidade, o entendimento das particularidades do comportamento dos indivíduos.
\end{abstract}

O público-alvo foi estabelecido na disciplina de Projeto Integrador I, referente à turma da $1^{\underline{a}}$ série, do Curso Técnico em Vestuário, integrado ao Ensino Médio, do campus Ibirama da Rede Federal, localizado no sul do país. A pesquisa foi realizada durante os 4 meses do último semestre acadêmico de 2013 e contou com um total de 28 participantes, sendo: um professor da disciplina (PD) e 27 alunos (AL). A escolha da disciplina foi intencional, por conveniência. A coleta de dados primários foi realizada através dos depoimentos $e$ análise das postagens e atividades desenvolvidas pelo professor e pelos estudantes do grupo de apoio à disciplina criado no Facebook.

Já a coleta de dados secundários foi realizada por meio da pesquisa documental e o conteúdo gerado durante a realização da aula na própria rede. A análise deu-se pela abordagem qualitativa, através do estudo dos comentários e atividades desenvolvidas e compartilhadas na rede social. $O$ aplicativo Wordle, foi outro recurso utilizado para identificação das palavras mais frequentes, presentes nos comentários, sobre a avaliação das redes sociais para a aprendizagem da disciplina.

Em relação ao perfil dos entrevistados, foi constado que a professora tem 27 anos, é bacharel em moda, especialista em moda e gestão, e mestranda em administração. Possui três anos de experiência em docência, sendo dois anos no 
ensino técnico integrado ao ensino médio e um ano no ensino superior. Quanto à experiência em ensino aliado às tecnologias, tem experiência em lecionar a disciplina de desenho técnico digital; no entanto, quanto ao uso de mídias sociais, é a primeira experiência da professora. Ela cursou a disciplina de TIC's do programa de mestrado e recebeu capacitação para a prática docente com mídias sociais e outras ferramentas digitais. Tem familiaridade com o uso do Facebook desde setembro de 2010 e com o uso da informática e recursos digitais desde 1995.

Já em relação aos estudantes, o gênero predominante foi o feminino, a maioria não exerce atividade extraclasse remunerada, e não recebe auxílio estudantil financeiro ou bolsa.

\section{Resultados}

A análise da pesquisa está subdividida em duas etapas. A primeira etapa apresenta a estruturação dos dados coletados. A segunda etapa é constituída da análise quantitativa e descritiva dos dados e, posteriormente, apresenta o estudo qualitativo dos depoimentos dos alunos participantes do grupo.

\section{Estruturação do grupo da disciplina no Facebook}

Servindo de instrumento para esta pesquisa, um grupo de Facebook foi criado para oferecer suporte à disciplina de Projeto Integrador, que tem por objetivo a elaboração e execução de um projeto que envolve os componentes curriculares profissionalizantes do primeiro ano, composto por: história do vestuário, tecnologia da costura, tecnologia têxtil, tecnologia do risco e corte, modelagem I e desenho técnico. Estes componentes são ofertados aos alunos para a aplicação dos conhecimentos adquiridos nas disciplinas técnicas, reforçando o processo de ensino-aprendizagem.

Vislumbra-se com a disciplina de Projetor Integrador I, o envolvimento dos alunos em um projeto específico, levando em consideração a familiaridade que os mesmos têm com as tecnologias e redes sociais. Esses preceitos levam em consideração as concepções de Martín-Moreno (2004), Pettenati e Ranieri (2006) e Brandtzaeg e Heim (2007), de que as redes sociais exercem um papel auxiliar na aprendizagem colaborativa, que propicia o compartilhamento de conhecimento, interação e comunicação em grupo.

Desta forma, a professora propôs a utilização da ferramenta de grupo no 
Programa de Pós-graduação em Educação, Universidade Federal do Ceará Fortaleza-CE-Brasil

Facebook. Os alunos aceitaram prontamente a ideia, que corrobora com os dados de Educause (2007) sobre a abrangência de usuários da rede social Facebook. O grupo foi aberto por uma aluna e pela professora, que atuavam como administradoras e classificado como secreto, ou seja, apenas membros poderiam visualizar as postagens e o grupo. Sendo assim, cada aluno recebeu um convite feito pelos administradores. Esse trecho se alinha com o pensamento de Costa e Ferreira (2013) de que as redes sociais estreitam a relação professor-aluno e ampliam o espaço de sala de aula.

As atividades realizadas no grupo do Facebook incluíram informações sobre as aulas, compartilhamento da criação de outras ferramentas digitais utilizadas em sala (CorelDraw 15, Photoshop, YouTube), postagem dos exercícios realizados, atividades executadas além do ambiente escolar, postagens de materiais relevantes ao projeto pesquisado pelos alunos e discussões. De acordo com os resultados obtidos por Dotta (2011), Minhoto e Meirinhos (2011), Raupp e Eichler (2012), Costa e Ferreira (2013) e Quintanilha (2017), os ambientes de aprendizagem efetivos, eficazes e envolventes fazem parte do cotidiano discente e tendem a se tornar ferramentas pedagógicas efetivas e eficazes.

O grupo foi estruturado em seções: exercícios, fotos look do dia, fotos diversas, fotos do projeto de filmes brasileiros, avisos, reportagens, pergunta/votação, vídeo, eventos, integração e comentários. Foi permitida a publicação de informações que incluíam links, fotos e vídeos, em conformidade com Educause (2007) que versa sobre a diversificada gama de ferramentas e aplicativos para comunicação e interação presentes na rede social Facebook. Também foi permitido que os participantes compartilhassem recursos e obtivessem feedback dos outros alunos. Este recurso de publicação foi eficiente, pois a cada nova postagem todos os integrantes do grupo tinham acesso, possibilitando uma integração mais dinâmica e rápida entre os membros.

Com relação ao compartilhamento, os alunos realizaram a publicação das atividades feitas durante a aula, fotos das etapas das atividades e do dia a dia em sala como forma de documentar as tarefas. O resultado das atividades foi publicado no grupo através de formatos compatíveis com o Facebook, como arquivo.jpg para fotos e desenhos, textos que foram digitados diretamente no espaço reservado para esse fim e os vídeos que foram publicados por meio de um link do YouTube, em 
Revista Labor

Programa de Pós-graduação em Educação, Universidade Federal do Ceará

Fortaleza-CE-Brasil

consonância com as práticas e ferramentas utilizadas por Minhoto e Meirinhos (2011)

e Quintanilha (2017).

Com relação às discussões online, a realização das conversas foi feita através das postagens dos alunos e dos professores. O chat disponível no Facebook foi utilizado como apoio para sanar dúvidas das etapas de cada atividade, tornando o processo mais dinâmico. Também foi solicitado que cada participante postasse no grupo sua percepção acerca da utilização da ferramenta como suporte do processo de ensino-aprendizagem.

\section{Análises das atividades desenvolvidas}

Para analisar as atividades desenvolvidas foram levantadas as mensagens e conteúdos gerados durante a disciplina, tanto pelo professor quanto pelos estudantes. O conteúdo compartilhado gerou um total de 413 comentários e 330 postagens que foram analisadas e categorizados da seguinte forma: fotos (fotos look do dia; fotos diversas; fotos do projeto de filmes brasileiros); vídeos; avisos; reportagens; pergunta/votação; eventos; integração e comentários. A análise quantitativa pode ser observada a seguir, no quadro 1.

Quadro 1. Atividades desenvolvidas

\begin{tabular}{|l|c|c|c|c|}
\hline Seções & Estudantes (AL) & $\begin{array}{c}\text { Média de postagem por } \\
\text { aluno }\end{array}$ & $\begin{array}{c}\text { Professor } \\
\text { (PD) }\end{array}$ & Total \\
\hline Exercícios & 99 & 3,67 & - & 99 \\
\hline Fotos look do dia & 85 & 3,15 & - & 85 \\
\hline Fotos diversas & 8 & 0,3 & 1 & 9 \\
\hline $\begin{array}{l}\text { Fotos Projeto } \\
\text { filmes brasileiros }\end{array}$ & 14 & 1,56 & - & 14 \\
\hline Avisos & 11 & 0,41 & 07 & 18 \\
\hline Reportagens & 35 & 1,3 & 01 & 36 \\
\hline Pergunta/ votação & 6 & 0,22 & 1 & 7 \\
\hline Vídeo (link) & - & 0 & 4 & 4 \\
\hline Eventos & - & 0 & 4 & 4 \\
\hline Integração & 49 & 1,81 & 5 & 54 \\
\hline Total 1 & 307 & 11,37 & 23 & 330 \\
\hline Comentários & 318 & 11,78 & 95 & 413 \\
\hline Total 2 & 625 & 23,15 & 118 & 743 \\
\hline
\end{tabular}

Fonte: dados da pesquisa (2013)

Observa-se no quadro 1 que a maioria dos comentários corresponde às respostas dos alunos para as diferentes seções, como por exemplo, exercícios e atividade look do dia, reportagens e integração, assim como respostas aos 
Quadro 2. Atividades desenvolvidas

\begin{tabular}{|c|c|c|}
\hline Seções & Exemplo & Observação \\
\hline Exercícios & $\sum_{i=\infty}^{+\infty}$ & $\begin{array}{l}\text { A proposta de divulgação dos exercícios em uma plataforma } \\
\text { virtual colaborativa proporcionou aos alunos a possibilidade de } \\
\text { construção do conhecimento coletivo, como também de } \\
\text { colaboração. Exerceu um papel importante também no } \\
\text { desempenho da atividade, haja vista que os colegas poderiam } \\
\text { comentar os trabalhos expostos. }\end{array}$ \\
\hline Fotos look do dia & ing & $\begin{array}{l}\text { Esta atividade também teve ampla aceitação dos alunos, que } \\
\text { puderam compartilhar o interesse pela moda e se expressar } \\
\text { de maneira individual, desenvolvendo a criatividade e a } \\
\text { individualidade. }\end{array}$ \\
\hline Integração & 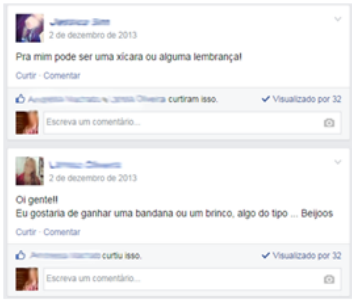 & $\begin{array}{l}\text { Esta seção surgiu espontaneamente, não foi incentivada pelo } \\
\text { professor. A adesão dos alunos ao grupo do Facebook foi } \\
\text { gradativa. Eles desenvolveram autonomia com a plataforma e } \\
\text { passaram a socializar dúvidas e a comunicar-se entre si de } \\
\text { forma pública dentro do grupo. Este é um exemplo das } \\
\text { postagens sobre o amigo secreto e demonstra a familiaridade } \\
\text { deles com a plataforma. }\end{array}$ \\
\hline Avisos & 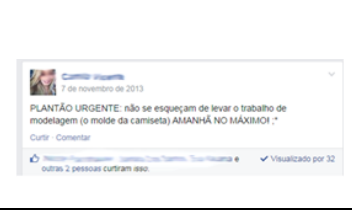 & $\begin{array}{l}\text { Nesta seção, houve o envolvimento dos alunos e do professor, } \\
\text { e a ferramenta se mostrou muito útil e eficaz para a } \\
\text { comunicação rápida e pontual. Os alunos recebiam as } \\
\text { notificações em seus celulares, o que resultou em um alto } \\
\text { índice de visualizações. }\end{array}$ \\
\hline Fotos diversas & DE & $\begin{array}{l}\text { A seção fotos diversas, como exemplo de compartilhamento } \\
\text { de informações, demonstra o ambiente de troca de } \\
\text { experiências e vivências dos alunos no ambiente virtual e } \\
\text { presencial. }\end{array}$ \\
\hline $\begin{array}{l}\text { Fotos Projeto } \\
\text { filmes brasileiros }\end{array}$ & & $\begin{array}{l}\text { Nesta seção, houve também a participação e } \\
\text { comprometimento dos alunos tanto na postagem do } \\
\text { desenvolvimento do trabalho, quanto no resultado final. }\end{array}$ \\
\hline
\end{tabular}




\begin{tabular}{|c|c|c|}
\hline Reportagens & $\begin{array}{l}21 \\
12\end{array}$ & $\begin{array}{l}\text { Os alunos, incentivados pelo professor, compartilharam no } \\
\text { grupo reportagens que os interessavam. Desta forma, } \\
\text { partilharam conhecimento e interesses mútuos entre si. }\end{array}$ \\
\hline Vídeo (link) & (2) (1) & $\begin{array}{l}\text { A seção do vídeo foi usada exclusivamente pelo professor, } \\
\text { sendo o vídeo considerado uma ferramenta interativa e } \\
\text { dinâmica. Os alunos visualizaram e comentaram o vídeo. }\end{array}$ \\
\hline Eventos & 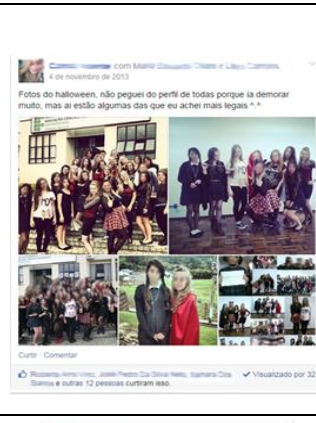 & $\begin{array}{l}\text { A sessão de eventos foi utilizada exclusivamente pelo } \\
\text { professor para agendar com os alunos as atividades a serem } \\
\text { entregues tanto no grupo do Facebook, quanto } \\
\text { presencialmente. Halloween Fashion Day é um exemplo de } \\
\text { atividade que foi organizada no grupo, informando os alunos } \\
\text { de como seria realizada a atividade. Eles customizaram as } \\
\text { fantasias em casa e houve o evento presencial na instituição. } \\
\text { Simultaneamente, os alunos postavam fotos em seus perfis do } \\
\text { Facebook e também no grupo. Foi uma atividade com adesão } \\
\text { de todos os alunos. }\end{array}$ \\
\hline Comentários & $\begin{array}{l}2= \\
y= \\
y=\end{array}$ & $\begin{array}{l}\text { Outro fator que demonstra a adesão à ferramenta pelo grupo } \\
\text { é o alto volume de comentários em relação às postagens que, } \\
\text { ao todo, foram } 330 \text {, somando } 413 \text { comentários. Houve intensa } \\
\text { atividade e interação entre o grupo. }\end{array}$ \\
\hline $\begin{array}{l}\text { Pergunta/ } \\
\text { votação }\end{array}$ & 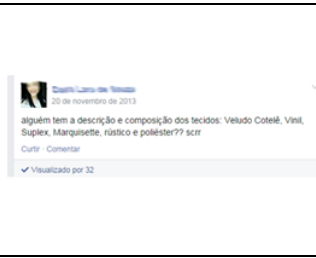 & $\begin{array}{l}\text { Esta seção foi utilizada tanto pelos alunos quanto pelo } \\
\text { professor. Em um ambiente com } 27 \text { alunos, a busca por um } \\
\text { denominador comum não é uma tarefa fácil. Nesta proposta } \\
\text { de enquete, eles puderam votar e argumentar. O resultado foi } \\
\text { objetivo e se mostrou uma ferramenta importante para a } \\
\text { tomada de decisão do grupo e do professor. }\end{array}$ \\
\hline
\end{tabular}

Fonte: dados da pesquisa (2013)

A seção intitulada exercícios consistia em três atividades individuais, nas quais os estudantes desenvolveram desenhos no software Corel Draw X5. Para fins de avaliação, os estudantes foram orientados pela professora a postar no grupo, enviar por e-mail ou imprimir as atividades. Nota-se a adesão dos alunos às publicações do grupo com uma média de 3,67 postagens, que superaram a média de três posts por estudante, conforme orientação da professora. Ainda houve uma ação espontânea dos alunos, que optaram por escrever os nomes nos desenhos publicados, reforçando a própria autoria, o que corrobora com os estudos de Almeida 
Programa de Pós-graduação em Educação, Universidade Federal do Ceará

Fortaleza-CE-Brasil

(2014). Percebeu-se também a preocupação com o visual do que era apresentado no grupo.

A seção fotos "look do dia" consistia em parte do trabalho de desenho planificado. Os alunos fizeram fotos de frente e de costas com os looks escolhidos por eles, para posterior representação através de desenho técnico. Mesmo com 3 opções de envio, assim como na atividade anterior, houve adesão dos alunos às postagens no grupo com uma média de 3,15 posts por aluno, superando a orientação da professora de duas postagens por estudante.

$\mathrm{Na}$ seção designada como "fotos diversas" foi registrado o cotidiano em sala de aula, como também os momentos de confraternização da turma, totalizando 8 publicações espontâneas, que compuseram a média de 0,3 postagem por aluno, uma frequência menor do que as médias das outras seções de fotos, fato esse que se alinha aos achados de Minhoto e Meirinhos (2011) de que há alunos mais engajados e que interagem mais, no entanto há também alunos que têm mais dificuldade de interação, tanto pela força do hábito, quanto por estarem inseridos em um contexto tradicional de ensino que incentiva a competição e a aprendizagem individual, ao invés da cooperação e a construção coletiva do conhecimento.

A seção "fotos do projeto de filmes brasileiros" consiste em um trabalho realizado em trio, no qual, os alunos foram orientados a publicar no grupo ou enviar por e-mail informações sobre o trabalho, as etapas em andamento e o resultado final. O volume de 14 postagens gerou uma média de 1,56 posts por aluno, o que demonstrou a adesão dos discentes pela postagem no grupo do Facebook. Houve uma menor adesão se comparado com as atividades individuais, devido às postagens terem sido realizadas em grupo e apenas um integrante do grupo fazia as atualizações.

A seção intitulada "avisos" foi usada por todos os participantes do grupo. Os avisos que foram repassados tratavam de assuntos da classe, alteração do calendário proposto e lembretes sobre as próximas aulas. Os alunos tiveram uma média de 0,7 publicação por estudante, enquanto a professora realizou 7 postagens.

Já a seção "reportagens" foi utilizada por todos os membros. A professora orientou que os alunos postassem ao menos uma reportagem de seu interesse pessoal em coerência com a temática de moda. Houve a adesão dos estudantes, que apresentaram média de 1,3 publicações, superando a expectativa de uma postagem 
por aluno. A professora postou uma reportagem, valor próximo à média dos alunos.

Houve por parte dos discentes, a iniciativa de realizar enquetes e votações para a tomada de decisão em grupo sobre questões cotidianas da turma. Foi incluída durante o processo de desenvolvimento do projeto a seção "pergunta/votação", com assuntos como a escolha da camiseta da turma, que poderia ser uma questão de conflito entre os alunos em sala de aula e que foi sanada por meio das votações e enquetes no grupo. A seção foi utilizada principalmente por eles, totalizando seis votações, sendo a média de uso por aluno de 0,22. Por se tratar de uma atividade coletiva, mesmo a média por aluno sendo baixa, apresentou um valor absoluto pelo grupo de seis votações, mostrando que houve efetividade da ferramenta em auxiliar na tomada de decisões em grupo, visto a adesão da turma em participar das votações.

A seção "vídeo" foi utilizada exclusivamente pelo professor. A postagem do professor envolveu o link do canal criado no YouTube, que totalizou dois vídeos sobre o projeto integrador e sua plataforma online. As outras postagens foram relacionadas aos vídeos sobre mídias sociais e tecnologias digitais aliadas à moda.

A seção "eventos" foi utilizada unicamente pelo professor, agendando com os alunos os períodos de postagens das atividades, como também eventos realizados fora da sala de aula, como foi o caso do dia do Halloween Fashion Day, que foi um evento organizado pela professora e os alunos na plataforma digital, mas realizado de forma presencial.

A seção "integração" foi utilizada tanto pelos alunos, média de 1,81 posts por aluno, quanto pela professora, com cinco postagens. Nesta seção, houve, a pedido da professora, a postagem da opinião dos alunos sobre a atividade no grupo do Facebook. Ainda assim, a média de 1,81 é superior à expectativa de uma postagem por aluno. Houve ainda publicações sobre o amigo secreto, também organizado através do grupo e realizado de forma presencial. No entanto, o evento foi organizado exclusivamente pelos alunos de forma espontânea.

Houve intensa participação dos discentes e do professor na seção comentários, quanto às postagens realizadas. Os alunos apresentaram valor absoluto de 318 comentários e média de 11,78 posts por aluno. O professor fez 95 comentários. Tanto como valor absoluto quanto média, a seção comentários foi a que obteve maior frequência de uso, o que demonstra intensa comunicação por meio da plataforma do Facebook. 
Em uma segunda etapa de análise, a partir da atividade, os alunos foram incentivados a comentar a utilização da rede social, Facebook, no processo ensinoaprendizagem da disciplina. Os depoimentos foram compilados em um único texto e submetidos ao aplicativo Wordle, o qual transforma um texto em uma nuvem de tags (word cloud ou lista ponderada em design visual), que é uma representação visual de dados de texto. Os tags são, geralmente, palavras isoladas, e a importância de cada tag é mostrada com o tamanho da fonte ou cor. Este formato visual é útil para perceber os termos mais proeminentes e para a localização de uma expressão, além de determinar sua frequência relativa dentro do contexto.

Foi utilizada a fonte Teen e o formato horizontal como definições do aplicativo no processo de desenvolvimento da nuvem. No entanto, na primeira nuvem os resultados foram pulverizados, em função de cada aluno ter uma forma de escrever as palavras. O texto passou por adequação ortográfica, como também por agrupamento de termos próximos a fim de refinar a análise. $O$ resultado é apresentado na Figura 1, conforme imagem abaixo:

Figura 1 - Nuvem de tags

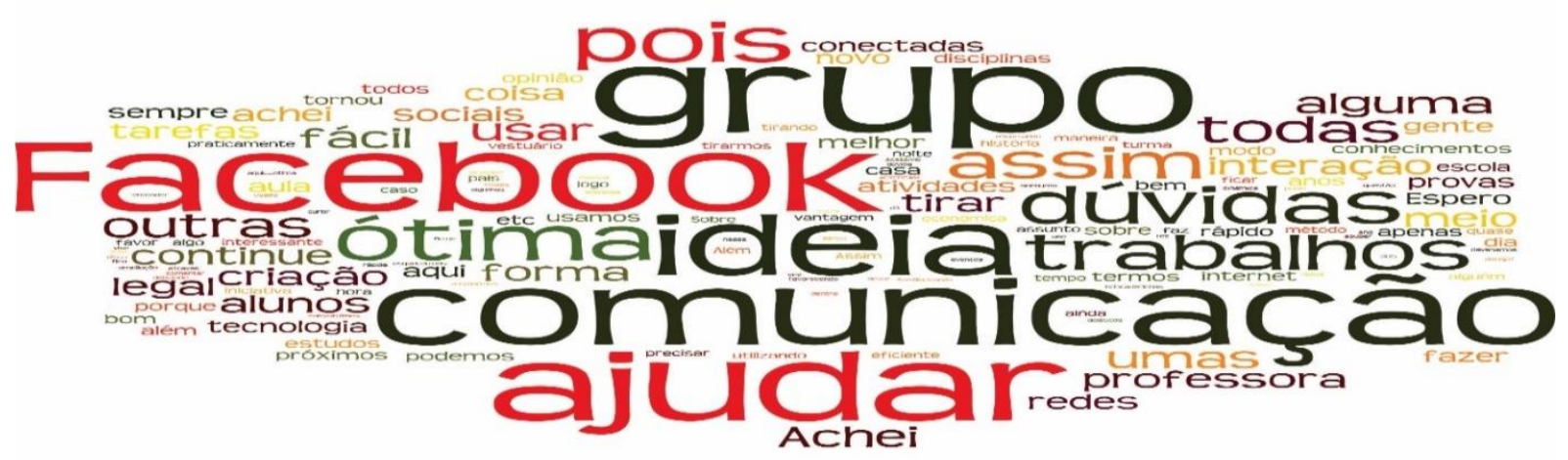

Fonte: dados da pesquisa (2013)

A Figura 1, em formato de nuvem de tags, apresenta as palavras mais frequentes em vários tamanhos e cores. As palavras foram classificados por tamanhos, de acordo com a constância em que aparecem no texto digitado, perceba que elas aparecem em três tamanhos: grande, médio e pequeno. As palavras menores, nesta escala, não foram classificadas devido à baixa frequência. Mas, outros termos podem ser visualizadas com facilidade, exemplo: Facebook, grupo, ideia, comunicação e ótima, isso acontece porque são as palavras citadas com maior frequência nos depoimentos dos estudantes. Por fim, as palavras de média frequência 

interação, fácil. E, por fim, os termos com menor frequência foram: continue, legal, criação, tecnologia, conectadas, atividades. Os termos com maior destaque refletem a aceitação dos alunos quanto ao uso do grupo do Facebook como uma ótima ideia para a comunicação da turma. Já as de médio impacto, fazem referência ao uso que os alunos fizeram da ferramenta, a forma como a rede social foi usada na execução de trabalhos, como ela auxiliou nas tarefas e dúvidas e como facilitou a interação entre a professora e os alunos.

Neste contexto, podemos dizer que as palavras com menor destaque podem significar que a criação do grupo, a conectividade dos alunos e o uso das tecnologias familiares aos alunos propiciaram um ambiente agradável e lúdico para a execução das atividades e das práticas de ensino-aprendizagem, mostrando que a continuidade deste processo seria aceita.

Fazendo a análise dos depoimentos, apenas um aluno respondeu que era indiferente ao uso do grupo no Facebook, por não ter um perfil na rede social. Esse aluno não tinha perfil em redes sociais devido à restrição familiar, e outros alunos postavam suas atividades identificando sua autoria. Os outros 23 depoimentos corroboram com a imagem criada pelo aplicativo Wordle, como verificado nos seguintes depoimentos:

\begin{abstract}
Achei muito vantajosa a ideia, pois a maioria de nós vive conectada com as redes sociais, podemos até dizer que nos comunicamos mais e melhor por elas do que pessoalmente. $\mathrm{O}$ grupo proporciona a vantagem de mantermos contato além da escola, lembrarmos umas às outras das responsabilidades, divulgar nossos trabalhos de forma mais acessível, participarmos mais dando nossa opinião e ajudando aos colegas, além de ampliarmos também nosso contato com as professoras, o que ajuda muito na hora de fazer os trabalhos de casa. Como melhoria, sugiro apenas que sejamos mais ativas (ainda) no grupo, colaborando umas com as outras renderemos cada vez mais (Aluno 1).
\end{abstract}

Com base no depoimento do aluno 1 e na nuvem de tags, o grupo no Facebook se apresenta como uma ferramenta colaborativa entre os alunos e o professor. O depoimento apresentado evidencia a colaboração do professor em sanar dúvidas fora da sala de aula, o que vai ao encontro dos estudos de Minhoto e Meirinhos (2011), Costa e Ferreira (2013) e Quintanilha (2017) de que o ambiente virtual estreita a relação aluno-professor, como também amplia o ambiente de sala de aula.

O processo de adaptação ao ensino médio técnico integrado se mostrou 
um desafio para os alunos da turma, que são provenientes do ensino fundamental em regime de meio período. Há recorrência nos depoimentos sobre essa adaptação a muitas disciplinas e atividades integrais, como evidenciado nos depoimentos:

Achei o grupo uma ideia muito boa, além de ser uma maneira de se comunicar, ajuda muito na organização dos estudos, pois fica muito mais fácil para tirar alguma dúvida e até mesmo lembrar algo importante. Assim ajudamos umas às outras, espero que continue assim (Aluno 2).

No depoimento do aluno 2 "Espero que continuemos assim até o terceiro ano. Estamos usando a tecnologia a nosso favor". Para o aluno 3, fica evidente que 0 grupo do Facebook auxiliou no agendamento das atividades e datas de entregas dos trabalhos, e na colaboração entre os alunos no esclarecimento de dúvidas e na realização das tarefas, que corroboram com os estudos de Dotta (2011) Minhoto e Meirinhos (2011), Costa e Ferreira (2013) e Quintanilha (2017) de que a interface virtual estimula a colaboração.

O depoimento do aluno 4 evidencia a percepção dos colegas de que o grupo do Facebook é uma plataforma familiar e divertida.

\begin{abstract}
Achei um trabalho muito legal, novo e interessante a criação do grupo no Facebook, porque tornou-se um meio de comunicação mais rápido da turma para termos um acompanhamento das aulas e atividades feitas, e o mais legal é que foi usado uma ferramenta diferente, como o Facebook que é algo que usamos apenas para brincadeirinhas e se tornou também por um certo aspecto um trabalho novo, que tem sua certa seriedade, mais com um ambiente mais descontraído e moderno, adorei a ideia (Aluno 4).
\end{abstract}

Os alunos se sentiram motivados ao executar as atividades, como evidenciado no depoimento: "Eu achei a ideia de usar o grupo mega boa, pois todas são ligadas na internet e foi um bom jeito de nos motivar". O depoimento do aluno 5 confirma os estudos de Alon et al. (2004 apud PANTELI, 2009) e Valck et al. (2006 apud PANTELI, 2009) que comunidades formadas nas redes sociais desenvolvem laços emocionais, elevando a frequência de acesso. Como também os estudos de Minhoto e Meirinhos (2011), Costa e Ferreira (2013) e Quintanilha (2017) de que um ambiente envolvente e cotidiano aos alunos melhora e amplia as possibilidades de aprendizagem e oferece ao educador outras formas de interação.

Esta classe apresentou algumas situações de conflito entre os alunos no primeiro semestre do curso, no entanto no depoimento do aluno 6: "[...] fazendo com que possamos compartilhar um pouco de nós entre si, acredito que isso serviu também para nos aproximarmos mais uma das outras, visto que assim fomos nos 

oportunidade de socialização e interação na qual não ocorreu nenhum ruído na comunicação entre aluno-professor, ou entre aluno-aluno, no grupo do Facebook. Ao invés disso, a plataforma oportunizou a interação e colaboração, resultando em envolvimento dos estudantes com o professor, o que auxiliou no processo de socialização da turma, que se alinha com os resultados de Minhoto e Meirinhos (2011) que as redes sociais digitais estimulam a aprendizagem colaborativa.

\begin{abstract}
Esse meio de comunicação - o Facebook - foi muito bem utilizado para um fim didático, no qual utilizou a tecnologia e praticidade das redes sociais, criando um grupo fechado no Facebook, para apresentar trabalhos e atividades de forma econômica, prática e acessível para todos(as) os(as) alunos(as). Foram feitos bons prazos, o que tornou possível a todas providenciar tempo e um momento para postar a atividade. Foi uma forma de interagirmos umas com as outras e estar sempre por dentro do assunto trabalhado em sala (Aluno 7).
\end{abstract}

Uma informação relevante, que emergiu dos dados, foi a declaração dos alunos entrevistados 1 e 7, de que a postagem dos trabalhos no grupo do Facebook se apresentou como uma proposta de viabilidade econômica. O grupo no Facebook exerceu função de inclusão social oportunizando as mesmas ferramentas em sala de aula e em contraturno a todos os alunos, o que corrobora com a afirmação de Selwyn (2003) sobre a amplitude de utilização das tecnologias atreladas ao maior acesso e consumo. Contemplando ainda as reflexões de Vermelho e Velho (2016) acerca da importância da tecnologia que auxilia na consolidação de uma prática social comprometida com a preservação da vida e do planeta. Como também o exposto por Faé e Sonza (2020) que abordou a necessidade de dar condições para que os adolescentes do ensino técnico profissionalizante desenvolvam um olhar crítico e autônomo sobre si mesmos e sobre a sociedade, que possibilitem práticas sociais interativas em que as questões éticas e humanistas sejam predominantes, tanto no ambiente escolar, quanto na ciência e em toda a sociedade.

\title{
Considerações Finais
}

A disciplina de Projeto Integrador I, suas características de integração, colaboração, aplicação prática do conhecimento teórico e desenvolvimento de projeto, que abarca as disciplinas técnicas do curso, oportunizou diversas atividades e um amplo envolvimento da turma. Fatores estes que favoreceram o sucesso da adoção do grupo do Facebook como ferramenta de apoio ao processo de ensino- 
O elevado número de adesões às atividades e a participação dos estudantes demonstram que houve um processo dinâmico de ensino. Percebeu-se também que os estudantes se sentiram motivados a participar das tarefas e postar seus achados no grupo, possibilitando a ampliação da discussão através das postagens.

Ao apresentar o trabalho ao grupo e não somente ao professor, obteve-se um resultado positivo no rendimento dos alunos, tendo em vista que ter um compromisso de entrega inferiu na qualidade do que foi exposto, no desenvolvimento da autoria, na adesão às atividades e na colaboração por parte dos estudantes. Isso foi possível, pois os alunos já estavam familiarizados com a realidade da comunidade virtual e confortáveis neste nível de interação. O conforto que o ambiente virtual propiciou à turma estimulou o desenvolvimento, tanto da integração presencial, que melhorou o relacionamento em sala de aula, quanto da autoria dos alunos.

Outro elemento a se destacar é o clima descontraído do Facebook, que possui um poder de atrair os jovens. O ambiente acadêmico/escolar utilizar e integrar este espaço descontraído como um meio de ensino-aprendizado, facilitou a aceitação do grupo criado dentro da plataforma. A comunicação professor-aluno foi favorecida pela familiaridade dos alunos com o digital, além da interação e integração da turma feita de forma satisfatória e a promoção da socialização dos integrantes por meio de interesses em comum, descobertos durante as discussões.

O ambiente virtual se adequou à realidade econômica dos alunos, propiciando uma aura de igualdade de oportunidades no processo de ensinoaprendizagem, no qual todos possuíam as mesmas ferramentas de interação.

A pesquisa apresentou limitações por se tratar de um estudo de caso, necessitando de outras pesquisas para confirmar ou negar os resultados em outros espaços e realidades. Há limitação pelo período analisado e ainda limitação cultural, pois em função de restrições familiares, um aluno da turma não participou do grupo no Facebook.

Sugere-se a realização de estudos com um número maior de respondentes, perfis diferentes, como também por um período maior de uso, utilizando-se do tratamento de dados quantitativos para averiguar pesquisas acerca do Facebook na educação. 
Os resultados encontrados, neste artigo, indicam que é necessário haver maior explanação do arranjo analisado com a realização de outras pesquisas. Sendo assim, futuros estudos podem averiguar se estudantes, no longo prazo, mantêm o rendimento e o interesse pela plataforma, bem como, se as turmas seguintes apresentariam o mesmo envolvimento e desempenho.

\section{Referências Bibliográficas}

ALMEIDA, Ana Maria. A autoria e a colaboração na aprendizagem da matemática por meio do recurso pedagógico do Facebook. Diálogos Educacionais em Revista, v. 5, n. 1, p. 28-47, 2014.

BONA, Rafael José et al. Transmídia como ferramenta educacional na área de Moda: relatos interdisciplinares acerca da produção de fashion films. Revista GEMInIS, v. 10, n. 3, p. 121-37, set./dez., 2019.

BRANDTZAEG, Petter Bae; HEIM, Jan. Initial context, user and social requirements for the Citizen Media applications: Participation and motivations in off- and online communities. Citizen Media Project, 2007.

COSTA, Ana Maria Simões Netto; FERREIRA, André Luiz Andrejew. Novas possibilidades metodológicas para o ensino-aprendizagem mediados pelas redes sociais Twitter e Facebook. Revista de Ensino de Ciências e Matemática, v. 3, n. 2, p. 136-47, 2013.

DIÓGENES, Maria Helena Bezerra da Cunha; SILVA, Lenina Lopes Soares; SOUZA, Adriana Aparecida de. Educação Profissional no Ensino Superior a Distância e o papel da tutoria para a formação humana: relato de uma experiência. Revista Labor, v. 1, n. 23, p. 202-22, 2020.

DOTTA, Sílvia. Uso de uma mídia social como ambiente virtual de aprendizagem. In: SIMPÓSIO BRASILEIRO DE INFORMÁTICA NA EDUCAÇÃO, 22., 2011, Aracaju. Anais... Porto Alegre: SBC, 2011. $10 \mathrm{p}$.

EDUCAUSE. 7 Things You Should Know About Facebook II, 2007. Disponível em: <http://net.educause.edu/ir/library/pdf/ELI7025.pdf>. Acesso em: 01 nov. 2014.

FAÉ, Janaína Scopel; SONZA, Andréa Poletto. O Corpo e suas relações: concepções em educação profissional e tecnológica. Revista Labor, v. 1, n. 23, p. 295-312, 2020.

GABRIEL, Martha. SEM e SEO: dominando o marketing de busca. São Paulo: Novatec, 2009.

GIL, Antônio Carlos. Métodos e técnicas de pesquisa social. São Paulo: Atlas, 2010. 
Programa de Pós-graduação em Educação, Universidade Federal do Ceará

Fortaleza-CE-Brasil

LEMOS, André; LÉVY, Pierre. O futuro da internet: em direção a uma ciberdemocracia planetária. São Paulo: Paulus, 2010.

LÉVY, Pierre. A máquina universo: criação, cognição e cultura informática. Porto Alegre: Artmed, 1998.

LIMA, Luciana et al. Narrativa transmídia na educação: experiência da Educoteca nas escolas públicas da cidade do Rio de Janeiro. Revista EducaOnline, v. 9, n. 3, p. 115, set./dez. 2015.

MARTÍN-MORENO, Cerrilo Quintina. Aprendizaje colaborativo y redes de conocimiento. In: Libro de actas de las IX Jornadas Andaluzas de Organización y Dirección de Instituciones Educativas. Granada: Grupo Editorial Universitário, 2004. p. 55-70.

MENLO PARK, Calif. Facebook, Inc. (Nasdaq: FB) today reported financial results for the quarter ended March 31. PRNewwire, 2020. Disponível em: $<$ https://investor.fb.com/investor-news/press-release-details/2020/Facebook-ReportsFirst-Quarter-2020-Results/default.aspx>. Acesso em: 23 jul. 2020.

MINHOTO, Paula; MEIRINHOS, Manuel. As redes sociais na promoção da aprendizagem colaborativa: um estudo no ensino secundário. Educação, Formação \& Tecnologias, v. 4, n. 2, p. 25-34, nov. 2011.

PANTELI, Niki. Virtual Social Networks: Mediated, Massive and Multiplayer Sites. Hampshire, UK: Palgrave-Macmillan, 2009.

PATRÍCIO, Maria Raquel; GONÇALVES, Vitor. Facebook: rede social educativa? In: ENCONTRO INTERNACIONAL TIC E EDUCAÇÃO, 1., 2010, Lisboa. Anais... Lisboa: Universidade de Lisboa, Instituto de Educação, 2010. p. 593-98.

PETTENATI, Mariachiara; RANIERI, Maria. Informal learning theories and tools to support knowledge management in distributed CoPs. Florence: EC-TEL Workshops Proceedings, 2006.

QUINTANILHA, Luiz Fernando. Inovação pedagógica universitária mediada pelo Facebook e YouTube: uma experiência de ensino-aprendizagem direcionado à geração-Z. Educar em Revista, n. 65, p. 249-263, jul./set. 2017.

RAUPP, Daniele; EICHLER, Marcelo Leandro. A rede social Facebook e suas aplicações no ensino de química. RENOTE, v. 10, n. 1, p. 1-10, 2012.

RICHARDSON, Roberto Jarry. Pesquisa Social: métodos e técnicas. 2. ed. São Paulo: Atlas, 1989.

SANTAELLA, Lucia. Comunicação ubíqua: repercussões na cultura e na educação. São Paulo: Paulus, 2013. 
Programa de Pós-graduação em Educação, Universidade Federal do Ceará

Fortaleza-CE-Brasil

SELWYN, Neil. Schooling the Mobile Generation: The future for schools in the mobilenetworked society. British Journal of Sociology of Education, v. 24, n. 2, p. 131-44, 2003.

SOCIALBAKERS. Facebook statistics directory. 2014. Disponível em: <https://www.socialbakers.com/statistics/facebook>. Acesso em: 01 dez. 2014.

SODRÉ, Muniz. Reinventando a Cultura: a comunicação e seus produtos. Petrópolis: Vozes, 1996.

VERMELHO, Sônia Cristina; VELHO, Ana Paula Machado. As pesquisas sobre redes sociais digitais no Brasil: análise do período de 2001 a 2012. Hipertextus Revista Digital, v. 15, p. 7-26, out. 2016.

WAISELFISZ, Júlio Jacobo. Lápis, borracha e teclado: tecnologia da informação na educação - Brasil e América Latina. Brasília: Instituto Sangari, MEC, 2007.

\section{Danila Cristiane Marques Sanches Dockhorn.}

Goioerê, Paraná, Brasil

Mestre em Administração pela Universidade Regional de Blumenau - FURB. Especialista em Moda e Gestão pelo SENAI Londrina, Bacharel em Moda pela Universidade Estadual de Maringá. Professora Ensino, Básico Técnico e Tecnológico no Instituto Federal do Paraná, Campus Goioerê no curso de Técnico em Produção de Moda. Coordenação do Projeto de Extensão CriaDança e dos projetos de ensino Fotografia Criativa e Desenho digital em software livre. Coordenadora do tcc do curso em técnico em Produção de moda. Membro do Núcleo de Arte e Cultura.

Email: danilasanches@gmail.com

Link do Lattes: http://lattes.cnpq.br/1539497782623192

\section{Júlio César da Silva.}

Mafra, Santa Catarina, Brasil

Doutor em Ciências Contábeis e Administração-FURB (2015). Mestre em Engenharia de Produção UFSC (2003) e Graduado em Administração-FERJ (1997). Docente e Pesquisador do Programa de Mestrado Profissional em Administração (PMPA) da Universidade do Contestado (UNC). Atua como Consultor empresarial e voluntário de entidades empresariais e culturais. Atua na docência com foco em Estratégias, Inovação, Marketing e Teorias das Organizações. Diretor da Cervejaria Maestro Ltda. Lecionou como professor colaborador no Mestrado em Administração PPGAd-FURB, como atividade do Pós-Doutorado. Foi professor visitante do Instituto Tecnológico y de Estudios Superiores de Monterrey-México e professor de Pós-Graduação da École des Mines - Saint Etienne- France Intituto Heliopolis e UNERJ.

Email: profjuliosilva72@gmail.com

Link do Lattes: http://lattes.cnpq.br/3274346178104121

\section{Maria José Carvalho de Souza Domingues}

Blumenau, Santa Catarina, Brasil

Maria José Carvalho de Souza Domingues possui graduação em Ciências da Administração pela Universidade Federal de Santa Catarina (1986), mestrado em Administração pela Universidade Federal de Santa Catarina (1991) e doutorado em Engenharia de Produção pela Universidade Federal de Santa Catarina (2003). É professora titular da Universidade Regional de Blumenau/FURB, no Departamento de Administração . Tem experiência na gestão universitária tendo atuado como Diretora do Centro de Ciências Sociais Aplicadas, Pró-Reitora de Ensino Médio, Graduação e Profissionalizante e coordenadora do Programa de Pós-Graduação em Administração da Universidade Regional de Blumenau/FURB. Nos Programas de Pós-Graduação em Administração e de Ciências Contábeis ministra disciplinas e desenvolve pesquisas relacionadas a gestão universitária e a tecnologias no ensino. Email: mariadomingues@furb.br

Link do Lattes: http://lattes.cnpq.br/1216257320382231 
Recebimento: $26 / 07 / 2020$

Aprovação: 20/11/2020

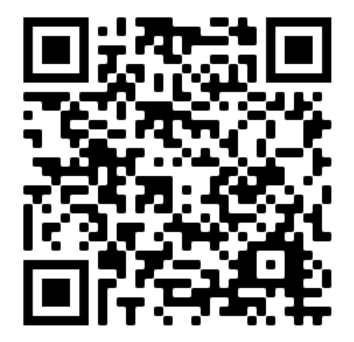

Q.Code

\section{Editores-Responsáveis}

Dr. Enéas de Araújo Arrais Neto, Universidade Federal do Ceará, UFC, Ceará, Brasil

Dr. Sebastien Pesce, Universidade de Orléans, França 